\title{
Melding Perspectives from Government, Commerce, and Engineering in an Interdisciplinary Undergraduate Minor in Technology Management and Policy
}

\author{
John K. Brown \\ University of Virginia
}

Under the primary leadership of its School of Engineering and Applied Science, the University of Virginia is developing a new interdisciplinary minor, titled "Technology Management and Policy." Open to all undergraduates, the TM\&P minor seeks to combine the disciplinary perspectives of Engineering, Commerce, and Government to achieve a comprehensive program of technology studies that is grounded in real-world issues. This paper outlines some of the challenges we have faced in creating this minor, and it outlines in detail two team-taught, interdisciplinary courses that will serve as cornerstones for all participants in the program.

In presenting this progress report (for we are still in an embryonic state), I have three chief goals: to outline our proposed model of integrative curricular reform, to discuss some of the conceptual and organizational challenges we have faced in this initiative, and to describe the long term purpose of the minors program. We hope that Virginia's program may serve as a model for similar efforts elsewhere. Equally we are still in the developmental stage, so any responses elicited by this report can influence our own progression.

In discussing an integrative, interdisciplinary program, the normal inclination is to open by describing all the various disciplines and approaches that will come together in novel, intellectually cohesive, and pedagogically exciting ways. I will get to that. First I want to outline a key limit to the scope of our program. Contrary to this session's title, our major endeavor is not to bring engineering and technology to the liberal arts, nor are we simply promoting technical literacy. Both are worthy goals to which we hope to contribute. But this program's unitary rationale is to study the formulation and impact of policies arising in the private and public sectors relating to the development, use, and regulation of technologies. This practice-oriented focus on technology policy is aimed to promote the utility and long-term vitality of the program.

The original architect and driving force behind Virginia's TM\&P program is Professor Paxton Marshall of UVA's Electrical Engineering Department. He began with the insight that the disciplinary structure of the large research university is a source of intellectual strength yet a practical and pedagogical weakness. Its strength derives from the deep reservoirs of knowledge and specialized expertise possessed by faculty with years of study and research in their disciplines. Yet those disciplinary boundaries exist only in the university; the "real world" as our students call it lacks such convenient yet constraining walls. In fact, students will graduate into professional environs where challenges and problems are multi-disciplinary. Practical solutions to such problems call for novel combinations of approaches, disciplines, and professions.

The growing technological dependence of modern business, government, and society at large contributes to this disjuncture between specialized undergraduate studies and practical professional challenges. In the present age "the world we inhabit has become in large part a technological system." 1 Yet the content of most undergraduate liberal arts studies scarcely acknowledges this undeniable truism. Conversely, engineers' role in the modern era is to apply scientific and technical knowledge to achieve specified human purposes through private enterprises or public agencies. Yet woefully little of their undergraduate education prepares engineering students to identify those purposes or understand the enterprises or agencies that guide their work.

As this audience is aware, these problems have hardly gone unnoted, receiving much comment and 
attention in the last decade particularly. In the early- 1980s, the Alfred W. Sloan Foundation began funding its "New Liberal Arts" program to bring engineering methodologies and technical literacy to liberal arts

undergraduates at a number of leading colleges. Similarly engineering schools like MIT and Georgia Tech have emphasized the social roots of technology by establishing programs in Science, Technology and Society. These programmatic efforts certainly have made a difference in broadening undergraduate education. 2 Indeed I teach in an STS-style program, the Division of Technology, Culture and Communication in Virginia's engineering school.

Although successful, such efforts to integrate the liberal arts with technical studies cannot be expected to redress all the educational needs of students entering technically-dependent professions and careers. In addition to bridges between the disciplines, we need focused initiatives yoked to practical concerns and professional training.3 Such pressing problems as America's declining industrial competitiveness, the gulf between technical and managerial personnel in industry, or the mastery of regulatory policies affecting technological change all call for such focused interdisciplinary initiatives.

In recent years, numerous reports have called for curricular reforms to address such problems. A 1994 report by the ASEE noted that

Engineers now operate in a world where their accomplishments are more often limited by societal considerations than by technical capacities .... Thus engineering education must take into account the social, economic, and political contexts of engineering practice. 4

In 1989 the MIT Commission on Industrial Productivity called for "a new cadre" of students possessing knowledge of real-world problems, ability to function as team members, and expertise beyond the confines of a single discipline. ${ }^{5}$ Such calls seek in part to address concerns noted in an October 1995 survey of senior managers at the Fortune 1,000 companies. This survey by Cornell's Johnson School of Management produced these results:

-58 percent of the senior executives interviewed noted a "cultural divide" between employees with technical training and those without it.

-68 percent of the respondents said their companies would be more competitive if more senior managers were technologically literate 6

The new Technology Management and Policy minor at UVA seeks to fulfill these needs by integrating the methodologies and concerns of three key fields: engineering, commerce, and government. The combination of these three fields deliberately orients the program around professional training. A focus on present-day concerns, case studies, and problem-solving methodologies provides a practical orientation. It is envisioned that the minor will provide common ground for students from Engineering, Commerce, and Government, allowing students to explore the contributions and limitations of each field (and others) in solving of real-world issues. Although students majoring in these three fields will likely dominate in the program, it will be available to undergraduates from across the university. Likewise, Engineering, Commerce, and Government will provide the bulk of the teaching staff, but faculty from other units are also participating actively.

The curricular structure of the program seeks to leverage student's experience in their major fields with significant exposure to courses that are truly interdisciplinary in their focus and methodologies. The program opens with two new synthetic courses, each to be team taught. The first, "Technology and the Product Development Lifecycle," is a micro-level course combining concerns from engineering and commerce. The second introductory offering is "Science and Technology Public Policy." It takes a macro-level view of technology policy, and it combines the perspectives of government, economics, and commerce. (Both these courses are described in further detail below.) All students entering the program will take these two courses, preferably in their second year. Next they will take two classes approved for the program in fields outside of their major (selected from a list of courses that are presently taught). For example, the non-engineering majors 
would take an introduction to systems engineering, while engineering students might study economics. The sequence will culminate in a year-long, two-semester course in which students will write senior theses on topics of their choice that integrate concerns in technology management and policy. This class should allow students to draw the diverse elements of the minor together in a research or design project that combines theory with practice.

To further illustrate interdisciplinary character of the program and its practical and professional orientations, the remainder of this paper will focus on describing the micro and macro introductory courses. These classes will be structured around case studies. Such cases will provide a factual framework that will draw students from the three main contributing fields into a common discourse. Equally the cases will serve as vehicles to illustrate the varied concerns and analytical methods of each contributing professor and discipline.7 The cases should serve as an ideal teaching tool to illuminate the interactive relations of engineering methods and issues, business concerns and approaches, and regulatory policy influences upon the character of technological developments.

In all their aspects, the two introductory courses emphasize the integrated nature of the minors program and of issues in technology management and policy generally. The micro course, "Technology and the Product Lifecycle," has been developed by a professor of mechanical engineering, Susan Carlson, and a commerce professor, John Leschke. Its main organizing principle is to consider technology, technology management, and product./process development within the firm. The course objectives are to:

-provide a common vocabulary of management, engineering, and technological terms.

-promote engineering students' appreciation of the market influences and business aspects involved in bringing a technological product to market.

-foster business students' awareness of the challenges and processes required to develop and commercialize a new technology or product.

-acquaint government students with the impacts of public policy on decision making within the firm.

The course is built around the "life cycle" construct which allows students to see how technology emerges from basic science (filtered through industrial research and managerial choices), how products emerge from perceived technological possibilities, how managers and public policy actors influence the adoption of new technologies in the market, and how products and technologies become obsolete or are replaced. The key issues covered in the course center on elements from commerce and engineering: including the nature of market research, managing research and development, concurrent engineering, economies of scale and scope, financial analysis, maturation of products and technologies, and product portfolios in declining markets. Illustrating these issues will be case studies on such topics as: parameters for evaluating industrial research projects, how firms categorize emerging technologies, and methods of market research for novel products.

In contrast to this firm-level focus, the other introductory course, "Science and Technology Public Policy," takes a much broader canvass. Developed by Professor James Savage of UVA's Government Department in consultation with engineering and commerce faculty, it considers the development and influence of public policies aimed at promoting and regulating science and technology. Focusing primarily on American federal policies, this course will explore such aspects of macro-level policy as: the justifications for federal efforts to promote and regulate science and technology, the players involved in formulating policies affecting science and technology, government support for innovation, and the impact of markets and politics on evolving policy stances. Course objectives include:

-promoting engineering students' awareness of the regulatory and policy influences on industrial practice and technological change.

-fostering commerce students' understanding of the ways in which policy decisions affect decision making by individuals, firms, and markets.

-acquainting government students with the benefits and limitations of legislative policies and administrative regulations on technological innovation, engineering practice, and industrial competitiveness. 
This course surveys the origins, rationale, development, and effects of federal public policies relating to science and technology. As such, its core is essentially a traditional government class, however, it includes historical perspectives, discussion of cost/benefit analyses, and other analytical methods from economics. Again, such disciplinary concepts and perspectives will be integrated by the use of case studies as a primary teaching tool. Case topics under consideration or development include: the effects of FDA policy on the research and development efforts of drug companies, corporate industrial research efforts in light of anti-trust policies, and intellectual property issues relating to software development.

In combination, the product lifecycle class and the science and technology course will acquaint students from the different major fields with the terminology, analytical methods, and typical concerns of professionals in engineering, industry, and government today. We anticipate that our reliance on cases will bring theoretical issues to life and engender students' excitement and interest. Each course will be team taught to ensure its interdisciplinary character. We hope, however, that the students themselves will foster effective integration of the topics by actively sharing the disciplinary perspectives and concerns of their major fields. If engineering, commerce, and government majors will share their specialized knowledge and learn from each other in the classroom, this will do as much as the instructors can to enrich all the participants.

Equally important, the minor seeks to demonstrate how and why professional perspectives on any given issue necessarily differ. Whether our graduates pursue careers in engineering, management, or government, success in their careers will depend in large measure upon an ability to understand and work harmoniously with professionals from a range of fields. Higher education is the chief instrument of training for professional fields. Universities will better serve the students and the professions by fostering understanding and dialogue between them.

This resume of the two core courses necessarily is somewhat general, since we will not formally launch our program until the Fall of 1996. The courses' content also remains flexible to accommodate the different interests and specialties of the teaching staff. In the first year, professors from mechanical engineering and the commerce school will teach the product Iifecycle class; the policy course will be headed by professors from the government and systems engineering departments. The TM\&P program as a whole has received the approval of UVA's president and the endorsement of the deans of Engineering, Commerce, and the College of Arts and Sciences (overseeing the Government Department). We have the financial support from the university and are seeking additional funds for curricular development elsewhere. Very soon, we will have teachers, classes, and students. Our long term success, however, will depend upon the program making a significant contribution to students' understanding and to the intellectual life of the university.

As a minors program, this TM\&P initiative can have only a modest impact on the university as a whole, yet it should offer benefits of real consequence. The program will teach commerce and government students how engineers think. That is to say, they will learn to define problems rigorously, learn how new products or process are created, and learn the complex, integrated character of modern technological systems. In a sense then, such students will become "technically literate. "Our overall goals for this group are to demystify engineering practice and acquaint students from these majors with a basic understanding of engineering methodologies like systems analysis, risk assessment, and critical paths.

For engineering students, the TM\&P program will counterbalance an inclination to conceive of engineering as merely applied science. Instead it will place social needs and influences at the crux of their professional practice. Such coursework will also underscore the ambiguous, open-ended, and multifaceted character of real world engineering problems. On a more prosaic note, the minor will help engineering students construct a coherent package of liberal arts electives, making that liberal education into a vital component of professional study. Finally it should engender habits of critical inquiry that can serve as a basis for lifelong learning.

For all its participants, this course of study insists that pressing social, industrial, and policy concerns are a legitimate focus of undergraduate education. Such issues as environmental protection, the role of innovation in productivity growth, and the effects of regulatory policies on technological change and economic 
competitiveness are all fundamentally important questions in our modern political economy. We must adapt our traditional models of education -- in both engineering and the liberal arts -- so that our graduates are better prepared to address such problems. Implicitly the TM\&P program emphasizes the ethical duty of all professionals to address such concerns. Indeed this initiative is predicated on the belief that universities and their faculties also share that duty to address real social needs.

\section{References}

1. Elting E. Morison, "The New Liberal Arts, Creating Novel Combinations Out of Diverse Learning," Change, 18, \#2 ((March/April, 1986): 8.

2. For a description of the Sloan New Liberal Arts program, see John G. Truxal, "Learning to Think Like an Engineer," and Robert Kanigel, “Technology as a Liberal Art," Change, 18, \#2 ((March/April, 1986): 10-30.

3. Some universities have begun such focused programs; for example MIT has its Technology Management and Policy Program, and similar graduate degree programs exist at Princeton, Harvard, and Stanford. Undergraduate programs at Carnegie Mellon and Washington University integrate engineering training with policy concerns, yet they are primarily designed for engineering majors. The TM\&P initiative at UVA seeks to create a genuinely equal collaboration between faculty and undergraduates from Commerce, Engineering, and Government.

4. ASEE Project Report, "Engineering Education for a Changing World: Using Partnerships to Respond to New Needs in Engineering Education," ASEE Prism, 4, \#4 (December, 1994): 24

5. Michael L. Dertouzos, et. al., Made in America, (Cambridge: MIT Press, 1989), p. 157

6. "Report on the 'Science Gap' in Corporate Management," (Executive Summary), The Johnson Graduate School of Management, Cornell University, (October, 18, 1995).

7. For the nature and uses of the case method in engineering coursework, see Larry G. Richards, et. al., "Promoting Active Learning with Cases and Instructional Modules," Journal of Engineering Education, 84, \#4 (October, 1995): 375-81.

\section{Biographic Information}

JOHN K. BROWN is an Assistant Professor in the Division of Technology, Culture and Communication in the School of Engineering and Applied Science at the University of Virginia. His research focuses on the history of engineering practice. He is the author of The Baldwin Locomotive Works, 1831-1915: A Study in American Industrial Practice (Johns Hopkins University Press, 1995). 